OPEN ACCESS

Edited by:

Sungsoo Park

Korea University, South Korea

Reviewed by:

Xu Zekuan,

Nanjing Medical University, China

Chang Min Lee,

Korea University, South Korea

Kazutaka Obama,

Kyoto University, Japan

*Correspondence:

Zhongtao Zhang

zhangzht01@126.com

Specialty section:

This article was submitted to

Surgical Oncology,

a section of the journal

Frontiers in Oncology

Received: 18 September 2020

Accepted: 04 December 2020

Published: 21 January 2021

Citation:

Tian P, Liu Y, Bian S, Li M, Zhang M,

Liu J, Jin L, Zhang P and Zhang Z

(2021) Laparoscopic Proximal

Gastrectomy Versus Laparoscopic

Total Gastrectomy for Proximal

Gastric Cancer: A Systematic

Review and Meta-Analysis.

Front. Oncol. 10:607922.

doi: 10.3389/fonc.2020.607922

\section{Laparoscopic Proximal Gastrectomy Versus Laparoscopic Total Gastrectomy for Proximal Gastric Cancer: A Systematic Review and Meta-Analysis}

\author{
Peirong Tian, Yang Liu, Shibo Bian, Mengyi Li, Meng Zhang, Jia Liu, Lan Jin, \\ Peng Zhang and Zhongtao Zhang*
}

Department of General Surgery, Beijing Friendship Hospital, Capital Medical University and National Clinical Research Center for Digestive Diseases, Beijing, China

Background: To compare laparoscopic proximal gastrectomy (LPG) and laparoscopic total gastrectomy (LTG) with regard to outcomes, including efficacy and safety, in patients with proximal gastric cancer.

Methods: Original English-language articles comparing LPG and LTG for proximal gastric cancer up to November 2019 were systematically searched in the Embase, PubMed, Cochrane Library, Web of Knowledge, and ClinicalTrials.gov databases by two independent reviewers. Our main endpoints were surgery-related features (operation time, blood loss, harvested lymph nodes, and postoperative hospital stay), postoperative complications (anastomotic leakage, anastomotic bleeding, anastomotic stenosis, and reflux esophagitis), and oncologic outcomes (5-year overall survival and recurrent cancer).

Results: Fourteen studies including a total of 1,282 cases (510 LPG and 772 LTG) were enrolled. Fewer lymph nodes were harvested (WMD $=-13.33,95 \% \mathrm{Cl}:-15.66$ to -11.00 , $P<0.00001)$ and more postoperative anastomotic stenosis (OR $=2.03,95 \% \mathrm{Cl}: 1.21$ to 3.39, $P=0.007$ ) observed in LPG than LTG. There were no significant differences in other explored parameters between the two methods. However, based on a subgroup analysis of digestive tract reconstruction, LPG with esophagogastrostomy (LPG-EG) had shorter operative time $(\mathrm{WMD}=-42.51,95 \% \mathrm{Cl}$ : -58.99 to $-26.03, P<0.00001)$, less intraoperative blood loss (WMD $=-79.52,95 \% \mathrm{Cl}$ : -116.63 to $-42.41, P<0.0001)$, and more reflux esophagitis ( $\mathrm{OR}=3.92,95 \% \mathrm{Cl}: 1.56$ to $9.83, P=0.004$ ) than was observed for LTG. There was no difference between LPG performed with the double tract anastomosis/double-flap technique (DT/DFT) and LTG.

Conclusion: LPG can be performed as an alternative to LTG for proximal gastric cancer, especially LPG-DT/DFT, with comparable safety and efficacy.

Keywords: laparoscopic total gastrectomy, laparoscopic proximal gastrectomy, proximal gastric cancer, metaanalysis, systematic review 


\section{INTRODUCTION}

Gastric cancer remains the fifth most frequently diagnosed cancer and the third most common cause of cancer-related death worldwide, especially in Eastern Asia, Eastern Europe, and South America $(1,2)$. The epidemiological characteristics of gastric cancer have changed over the last several decades. Although the overall incidence of gastric cancer has decreased, the incidence rate of proximal gastric cancer has been increasing in both Western and Asian countries $(3,4)$. Despite developments in multimodal therapy strategies, such as chemotherapy, radiotherapy, targeted therapy, and immunotherapy, the most effective therapy for potentially curable proximal gastric cancer has remained surgical resection (5). With the rapid development of minimally invasive surgery, clinical applications involving laparoscopic gastrectomy have been widely accepted as standard surgeries for proximal gastric cancer (6, 7). There are two main types of laparoscopic surgical strategies: laparoscopic total gastrectomy (LTG) and laparoscopic proximal gastrectomy (LPG).

Compared to LPG, LTG can achieve a longer tumor-free distal resection margin and more radical lymphadenectomy, which seem to have better curative effects. More significantly, compared with LPG, LTG has few postoperative complications (8). However, in many retrospective studies, compared to LPG, LTG has shown only slightly superior results in this poor-outcome cancer (9-13). Additionally, anemia, weight loss, and symptoms, such as heart burn, nausea, and vomiting (known as postgastrectomy syndrome), are frequent postoperative complications in LTG patients and must be considered (14-17). In contrast, LPG has theoretical advantages in terms of postoperative nutritional status and anemia because the gastric reservoir is preserved and gastric acid secretion and intrinsic factors are maintained (18-22). However, an unavoidable consequence of traditional LPG-EG is reflux esophagitis, which is the main factor that reduces postoperative quality of life in this population. Thus, the adequate surgical technique for the treatment of proximal gastric cancer remains controversial. While the feasibility and safety of these two methods have been demonstrated in a variety of studies, most of them were singlecenter studies with small sample sizes and limited follow-up periods. Previous meta-analysis relied on data mostly obtained from conventional open surgery (23-27). To overcome these limitations, a meta-analysis of studies comparing LPG and LTG for proximal gastric cancer should be performed. Therefore, we conducted this systematic review and meta-analysis to systematically review the surgery-related features, postoperative complications and oncologic outcomes of LPG and LTG for proximal gastric cancer.

\section{METHODS}

This systematic review was performed according to the PRISMA statement.

\section{Literature Search}

The literature published in English from the inception dates of each of the following electronic databases up to November 2019 was searched: PubMed, Embase, Cochrane Library, Web of Knowledge, and ClinicalTrials.gov. The keywords "laparoscopic," "proximal gastrectomy," "total gastrectomy," and "proximal gastric cancer" were used. Search strings of PubMed were as follows: $(((()(((($ stomach neoplasm[MeSH terms])) OR (cancer of stomach)) OR (cancer of the stomach)) OR (gastric cancer)) OR (gastric neoplasms)) OR (neoplasms, gastric)) OR (neoplasms, stomach)) OR (stomach cancer)) AND $(((()((()($ laparoscopy [MeSH terms]) OR (celioscopy)) OR (laparoscopic assisted surgery)) OR (laparoscopic surgery)) OR (laparoscopic surgical procedure)) OR (peritoneoscopy)) OR (procedure, laparoscopic surgical)) OR (procedures, laparoscopic surgical)) OR (surgery, laparoscopic)) OR (surgical procedure, laparoscopic)) OR (surgical procedures, laparoscopic))) AND ((total gastrectomy[title/abstract]) AND (proximal gastrectomy[title/abstract])). All titles, abstracts and related citations were scanned and reviewed. Reference lists from primary studies and review articles were also examined manually to search for additional publications. Two authors individually conducted the literature search and crosschecked their search results.

\section{Study Selection}

Duplicate search results were first excluded. Studies were included in this research according to the following criteria: 1) clinical studies that compared LPG with LTG for proximal gastric cancer, and 2) LPG/LTG that was performed with either a laparoscopy-assisted or total laparoscopic approach.

Papers meeting any of the following criteria were excluded: 1) studies including other types of gastric resection, unless the data were presented separately; 2) conference abstracts, reviews, comments, case reports, noncomparative studies, nonrelevant topic papers, nonEnglish papers, and animal studies; and 3) duplicated publications or publications that did not provide sufficient data.

\section{Quality Assessment of the Studies}

Since all the included studies were nonrandomized, the Newcastle-Ottawa Scale (NOS) was used to judge study quality, as recommended by the Cochrane Collaboration. The maximum score achievable on the NOS is nine stars (four for the selection process, two for comparability, and three for exposure/ outcome), with a score of five or more indicating high quality. The results are presented in Table 2. Any discrepancies were resolved by consulting a consensus reviewer.

\section{Methods of Review}

Relevant data from the included studies were extracted, critically appraised independently by two investigators using a structured sheet, and entered into a database. Any disagreements were resolved though discussions among the author group. The characteristics of the study and the patients were documented and are presented in a table format. We extracted operation time, intraoperative blood loss, the number of harvested lymph nodes, and the length of postoperative hospital stay to assess the effectiveness of surgical procedures and postoperative recovery. Postoperative complications, including anastomotic bleeding, leakage, stenosis, and reflux esophagitis, were compared. The rate of tumor recurrence and 5-year overall survival (OS) were used to estimate the safety of LPG and LTG. If necessary, the primary authors were contacted to retrieve further information. 


\section{Statistical Analysis}

Continuous variables, when both means and standard deviations (SDs) were presented, were assessed using the weighted mean difference (WMD) with 95\% confidence intervals (CIs). If the study provided the median, range and size of a sample, we estimated the means and SDs according to published methods $(28,29)$. Dichotomous variables were calculated using the odds ratio (OR) and 95\% CIs. Fixed-effects models were used for studies with low heterogeneity, while random effects models were used for those with high heterogeneity. Cochran's Q-test was used to assess heterogeneity, and $P<0.1$ was defined as significant. A sensitivity analysis was applied by removing individual studies from the data set and analyzing the effect on the overall results to identify sources of significant heterogeneity. Publication bias was evaluated using funnel plots and statistically tested by Begger's test and Egger's test. All statistical calculations were performed using Review Manager 5.3 (The Cochrane Collaboration, Oxford, UK) and STATA15.0 (Stata Corporation, College Station, TX, USA). A two-trailed value of $P<0.05$ was considered statistically significant.

\section{RESULTS}

\section{Search Results}

The search strategy identified 1,632 articles that mentioned the use of LPG and LTG for proximal gastric cancer. After carefully screening the titles, abstracts, and full texts, 14 articles were selected based on the inclusion and exclusion criteria (30-43). Figure 1 presents a flow diagram that details the selection process. All studies included were observational, and no randomized controlled studies were identified. The NOS was used to evaluate the quality of each study, and each study had a score of $>5$ points.

\section{Characteristics of Included Studies}

A total of 1,282 patients were involved in the meta-analysis (510 patients underwent LPG and 772 patients underwent LTG). The main characteristics of the fourteen studies included in the analysis are summarized in Table $\mathbf{1}$. All articles were published from 2007 to 2019; among these studies, nine trials were from Japan, four were from Korea, and one was from China.

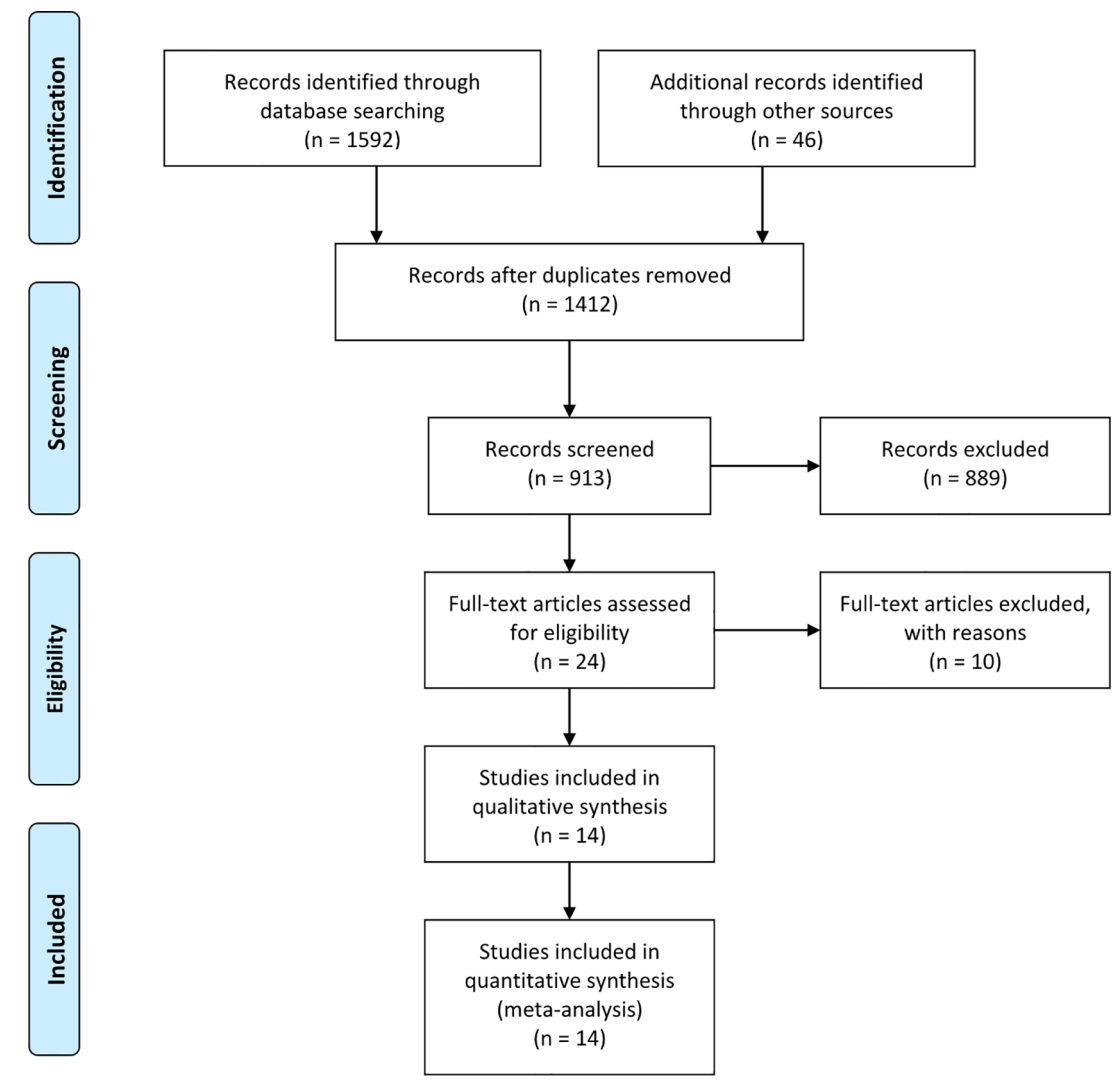

FIGURE 1 | Articles identified with criteria for inclusion and exclusion. 
TABLE 1 | Characteristics of included studies

\begin{tabular}{|c|c|c|c|c|c|c|c|c|c|c|c|c|c|c|c|}
\hline \multirow[t]{2}{*}{ Reference } & \multirow[t]{2}{*}{ Country } & \multirow[t]{2}{*}{ Approach } & \multirow{2}{*}{$\begin{array}{l}\text { Sample } \\
\text { size }\end{array}$} & \multirow{2}{*}{$\begin{array}{c}\text { Age } \\
\text { (years) }\end{array}$} & \multirow{2}{*}{$\begin{array}{l}\text { Gender } \\
\text { (M/F) }\end{array}$} & \multirow{2}{*}{$\begin{array}{c}\mathrm{BMI} \\
\left(\mathrm{kg} / \mathrm{m}^{2}\right)\end{array}$} & \multirow{2}{*}{$\begin{array}{l}\text { Tumor size } \\
\quad(\mathrm{cm})\end{array}$} & \multicolumn{3}{|c|}{ TNM stage } & \multicolumn{2}{|c|}{ Lymphadenectomy } & \multirow[t]{2}{*}{ Reconstruction } & \multirow{2}{*}{$\begin{array}{l}\text { Follow-up duration } \\
\text { (months) }\end{array}$} & \multirow[t]{2}{*}{ NOS } \\
\hline & & & & & & & & IA & IB & II & D1+ & D2 & & & \\
\hline \multirow[t]{2}{*}{ Tanimura et al. (30) } & Japan & LTG & 72 & NR & $N R$ & $N R$ & $N R$ & NR & NR & $N R$ & NR & NR & $R-Y$ & $30(3.6-85.2)$ & 7 \\
\hline & & LPG & 38 & NR & NR & NR & NR & $N R$ & NR & NR & NR & $N R$ & EG, Jl & & \\
\hline \multirow[t]{2}{*}{ Ahn et al. (31) } & Korea & LTG & 81 & $59.7 \pm 11.8$ & $56 / 25$ & $23.6 \pm 3.4$ & $4.0 \pm 2.7$ & $\mathrm{NR}$ & NR & $N R$ & 70 & 11 & R-Y, EJ & $38.3 \pm 21.6$ & 8 \\
\hline & & LPG & 50 & $58.8 \pm 12.1$ & $36 / 14$ & $24.2 \pm 3.7$ & $2.8 \pm 1.3$ & NR & NR & NR & 50 & 0 & $E G$ & $44.0 \pm 17.9$ & \\
\hline \multirow[t]{2}{*}{ Kosuga et al. (32) } & Japan & LTG & 52 & $67(40-89)$ & $45 / 7$ & $23.6(19.0-42.8)$ & NR & 45 & 7 & 0 & 50 & 2 & R-Y, EJ & $37.6(3.5-71.3)$ & 8 \\
\hline & & LPG & 25 & $66(41-80)$ & $17 / 8$ & $22.3(17.7-28.0)$ & NR & 24 & 1 & 0 & 25 & 0 & $E G$ & $36.1(5.2-71.3)$ & \\
\hline \multirow[t]{2}{*}{ Kim and Kim (33) } & Korea & LTG & 17 & $60.9+12.9$ & $10 / 7$ & $23.4+5.0$ & $4.0+3.2$ & 12 & 3 & 2 & NR & NR & EJ & $N R$ & 7 \\
\hline & & LPG & 17 & $64.7 \pm 9.9$ & $14 / 3$ & $24.2 \pm 3.8$ & $2.2 \pm 1.0$ & 12 & 4 & 1 & NR & NR & DT & NR & \\
\hline \multirow[t]{2}{*}{ Hosoda et al. (34) } & Japan & LTG & 59 & $66.5 \pm 11.0$ & $41 / 18$ & $23.3 \pm 3.5$ & $5.1 \pm 2.7$ & 34 & 11 & 10 & 54 & $\mathrm{NR}$ & EJ & $42(12-71)$ & 9 \\
\hline & & LPG & 40 & $68.4 \pm 8.3$ & $32 / 8$ & $23.5 \pm 2.4$ & $2.8 \pm 1.2$ & 32 & 4 & 3 & 29 & $N R$ & EG & 37 (11-64) & \\
\hline \multirow{2}{*}{$\begin{array}{l}\text { Jung et al. } \\
\text { (35) }\end{array}$} & Korea & LTG & 156 & $58.7 \pm 10.8$ & $120 / 36$ & $23.9 \pm 3.3$ & $3.2 \pm 1.9$ & $\mathrm{NR}$ & NR & $N R$ & 86 & 70 & R-Y, EJ & $43.5 \pm 23.2$ & 8 \\
\hline & & LPG & 92 & $59.8 \pm 11.4$ & $77 / 15$ & $23.5 \pm 2.7$ & $2.4 \pm 1.3$ & NR & NR & NR & 92 & 0 & DT & $26.6 \pm 10.3$ & \\
\hline \multirow[t]{2}{*}{ Nishigori et al. (36) } & Japan & LTG & 42 & $64.4 \pm 12.2$ & $28 / 14$ & $22.8 \pm 3.6$ & NR & NR & NR & NR & 41 & 1 & R-Y, EJ & $50(2-98)$ & 9 \\
\hline & & LPG & 20 & $66.2 \pm 13.4$ & $15 / 5$ & $23.4 \pm 3.8$ & NR & $\mathrm{NR}$ & NR & NR & 17 & 0 & $E G$ & & \\
\hline \multirow[t]{2}{*}{ Hayami et al. (42) } & Japan & LTG & 47 & $69(41-84)$ & $34 / 13$ & $22.4(16.4-30.6)$ & $34.5(7-105)$ & 42 & 2 & 0 & 47 & NR & R-Y & 49 (18-62) & 8 \\
\hline & & LPG & 43 & $72(37-90)$ & $31 / 12$ & $23.7(18.2-36.2)$ & $25.0(8-70)$ & 32 & 7 & 4 & 43 & $N R$ & DFT & $25(12-40)$ & \\
\hline \multirow[t]{2}{*}{ Park et al. (37) } & Korea & LTG & 46 & $56.7 \pm 11.8$ & $22 / 24$ & $22.9 \pm 3.4$ & $3.2 \pm 1.9$ & 35 & 4 & 6 & NR & $N R$ & $R-Y$ & $47.5(7.0-67.4)$ & 8 \\
\hline & & $L P G$ & 43 & $64.1 \pm 12.2$ & $26 / 8$ & $23.1 \pm 3.2$ & $2.1 \pm 1.1$ & 29 & 1 & 3 & NR & $N R$ & DFT & $29.6(2.9-39.5)$ & \\
\hline \multirow{2}{*}{$\begin{array}{l}\text { Sugiyama et al. } \\
\text { (38) }\end{array}$} & Japan & LTG & 20 & $68.6 \pm 2.7$ & $17 / 3$ & NR & NR & 16 & 1 & 2 & NR & NR & $R-Y$ & 12 & 7 \\
\hline & & LPG & 10 & $65.6 \pm 3.8$ & $7 / 3$ & NR & NR & 8 & 1 & 1 & NR & NR & DT & 12 & \\
\hline \multirow{2}{*}{$\begin{array}{l}\text { Furukawa et al. } \\
\text { (39) }\end{array}$} & Japan & LTG & 48 & $63.5(29-82)$ & $35 / 13$ & $22.2(13.9-26.5)$ & $32(10-100)$ & \multicolumn{2}{|c|}{39} & 4 & 32 & 16 & $R-Y$ & 48.5 & 8 \\
\hline & & LPG & 27 & $70(59-84)$ & $22 / 5$ & $22.8(19.3-26.8)$ & $25(12-50)$ & \multicolumn{2}{|c|}{24} & 2 & 27 & 0 & DT & 30 & \\
\hline Nomura et al. (40) & Japan & LTG & 30 & $68.5 \pm 8.3$ & $21 / 9$ & NR & NR & 17 & 4 & 8 & NR & NR & $R-Y$ & 12 & 7 \\
\hline & & LPG & 30 & $67.5 \pm 8.7$ & $24 / 6$ & NR & NR & 22 & 6 & 2 & NR & NR & DT/JI & 12 & \\
\hline Kano et al. (41) & Japan & LTG & 78 & $66(41-84)$ & $66 / 12$ & NR & $30(1-75)$ & 63 & 11 & 2 & NR & NR & R-Y & 60 & 9 \\
\hline & & LPG & 72 & $67(30-88)$ & $47 / 25$ & NR & $28(2-125)$ & 61 & 6 & 3 & NR & NR & JI/DFT & 60 & \\
\hline Wang et al. (43) & China & LTG & 24 & $58.38 \pm 1.82$ & $15 / 9$ & $23.5 \pm 0.69$ & $2.12 \pm 0.27$ & 2 & 2 & 2 & NR & NR & R-Y & 12 & 7 \\
\hline & & LPG & 12 & $55.58 \pm 4.10$ & $6 / 6$ & $23.29 \pm 0.76$ & $1.74 \pm 0.17$ & 1 & 0 & 2 & NR & NR & DT & 12 & \\
\hline
\end{tabular}

LTG, laparoscopic total gastrectomy; LPG, laparoscopic proximal gastrectomy; BMI, body mass index; TNM, tumor, node, metastasis; NOS, Quality Assessment based on Newcastle-Ottawa Scale; R-Y, Roux-en-Y; EG, esophagogastrostomy; Jl, jejunal interposition; EJ, esophagojejunostomy; DT, double tract anastomosis (gastrojejunostomy and jejunojejunostomy); DFT, double-flap technique; NR, not reported. 


\section{Meta-Analysis Results Surgery-Related Features Operation Time}

All included studies (1,291 patients) provided data on operation time (30-43). No significant difference was found between these two groups (WMD $=-5.92,95 \% \mathrm{CI}:-23.66$ to $11.82, P=0.51$ ), and there was significant heterogeneity $\left(I^{2}=91 \%, P<0.00001\right)$ (Figure 2A, Table 2). In the subgroup analysis, no statistically significant differences were observed between the DT and DFT groups. However, the operative time was longer in the LTG group than in the LPG-EG group (WMD $=-42.51,95 \% \mathrm{CI}$ : -58.99 to $-26.03, P<0.00001$ ) (Figure 2A).

\section{Blood Loss}

Thirteen studies (1,257 patients) reported intraoperative blood loss volume (30-32, 34-43). No significant difference was observed between the two groups (WMD $=-24.30,95 \% \mathrm{CI}$ : -49.60 to $0.99, P=0.06)$, and the heterogeneity among the studies was significant $\left(I^{2}=84 \%, P<0.00001\right)$. In the subgroup analysis, the DT and DFT groups showed similar results except for the LPG-EG group (WMD $=-79.52,95 \% \mathrm{CI}$ : -116.63 to -42.41, $P<0.0001$ ) (Figure 2B).

\section{Harvested Lymph Nodes}

The quantities of harvested lymph nodes were included in nine studies (908 patients) and showed moderate heterogeneity $\left(I^{2}=\right.$ $41 \%, P=0.09)(30-35,37,38,42,43)$. The overall effect size favored the LTG group (WMD $=-13.33,95 \% \mathrm{CI}:-15.66$ to $-11.00, P<0.00001)$ (Figure 2C).

\section{Postoperative Hospital Stay}

Twelve studies (1,154 patients) provided data on postoperative hospital stay $(30-35,37,38,40-43)$. According to the randomeffects model, there was no significant difference between the two groups (WMD $=-1.12,95 \% \mathrm{CI}:-2.29$ to $-0.06, P=0.06$ ) (Figure 2D).

\section{Postoperative Complications}

Among the observed postoperative morbidities, there were no differences in the frequencies of anastomotic leakage and bleeding (Figures 3A, B, Table 2). The incidence of anastomotic stenosis was higher in the LPG group than in the LTG group ( $\mathrm{OR}=2.03,95 \% \mathrm{CI}: 1.21$ to $3.39, P=0.007$, Figure 3C). Nine studies (876 patients) reported results for reflux esophagitis $(31-36,39,40,42)$. There was no significant difference between the two groups $(\mathrm{OR}=1.87,95 \% \mathrm{CI}$ : 0.74 to 4.71, $P=0.18)$. The heterogeneity among the studies was moderate $\left(I^{2}=53 \%, P=0.03\right)$. In the subgroup analysis, compared to LPG-EG (OR $=3.92,95 \% \mathrm{CI}: 1.56$ to $9.83, P=$ 0.004), the incidence of reflux between the LPG-DT and LTG groups was not significantly different $(\mathrm{OR}=1.22,95 \% \mathrm{CI}$ : 0.34 to 4.37, $P=0.76$, Figure 3D).

\section{Oncologic Outcomes}

Five-Year Overall Survival Rates

Five homogenous $\left(I^{2}=39 \%, P=0.16\right)$ studies (690 patients) reported 5-year overall survival rates $(31,34-36,41)$. The results revealed that patients who had undergone LTG or LPG had similar 5-year overall survival rates $(\mathrm{OR}=1.04,95 \% \mathrm{CI}$ : 0.47 to 2.27, $P=0.93$, Figure 4A).

\section{Recurrence Rate}

Six studies reported data on recurrence and showed no heterogeneity $\left(I^{2}=0 \%, P=0.66\right)(30,32,34,35,37,39)$. No statistically significant differences were observed between the LPG and LTG groups (OR: 0.67, 95\% CI: 0.19 to $2.41 \mathrm{P}=0.54$, Figure 4B).

\section{Sensitivity Analysis and Publication Bias}

A sensitivity analysis was performed by excluding one study in turn to assess whether individual research influenced pooled ORs or WMDs. For every meta-analysis, the pooled ORs or WMDs were similar after each study was excluded, and this verified the stability of the meta-analysis.

In our study, Egger's tests were conducted to detect potential publication bias. The funnel plots for operative time, intraoperative blood loss, number of harvested lymph nodes, and length of postoperative hospital stay are shown for more than ten studies. According to the outcomes of shown in the funnel plot graphics, no indication of significant publication bias was observed $(P>0.05)$ (Figure 5).

\section{DISCUSSION}

The present meta-analysis assessed whether LPG is an acceptable alternative to LTG in patients with proximal gastric cancer. Our results suggest that compared to LTG, LPG resulted in fewer harvested lymph nodes. However, with regard for other parameters, there were no significant differences between the two methods. Based on the subgroup analysis of digestive tract reconstruction, however, classic LPG-EG had shorter operative time, less intraoperative blood loss and more reflux esophagitis. LPG-DT/DFT overcomes these shortcomings and has a similar prognosis. Recently, several meta-analyses have shown the superiority of LTG over LPG; however, these articles focused only on open surgery and did not evaluate laparoscopic surgery, and the use of different digestive tract reconstruction methods was not accounted for. With the development of laparoscopic techniques, the application of laparoscopic gastrectomy has been widely accepted, and several high-quality articles comparing LPG with LTG have recently been published. We therefore performed this meta-analysis to estimate the value of LPG in patients with proximal gastric cancer based on different reconstruction methods.

The results of this study show that the overall operative time and blood loss did not differ between LPG and LTG. There was a high degree of heterogeneity among the studies, and the results of the subgroup analyses suggest that this heterogeneity may be the result of differences in reconstruction methods. Traditional LPGEG had shorter operative times and less blood loss; however, no statistically significant differences were observed between LPGDT/DFT and LTG with regard for these parameters. The longer operative times and increased blood loss may be due to the 


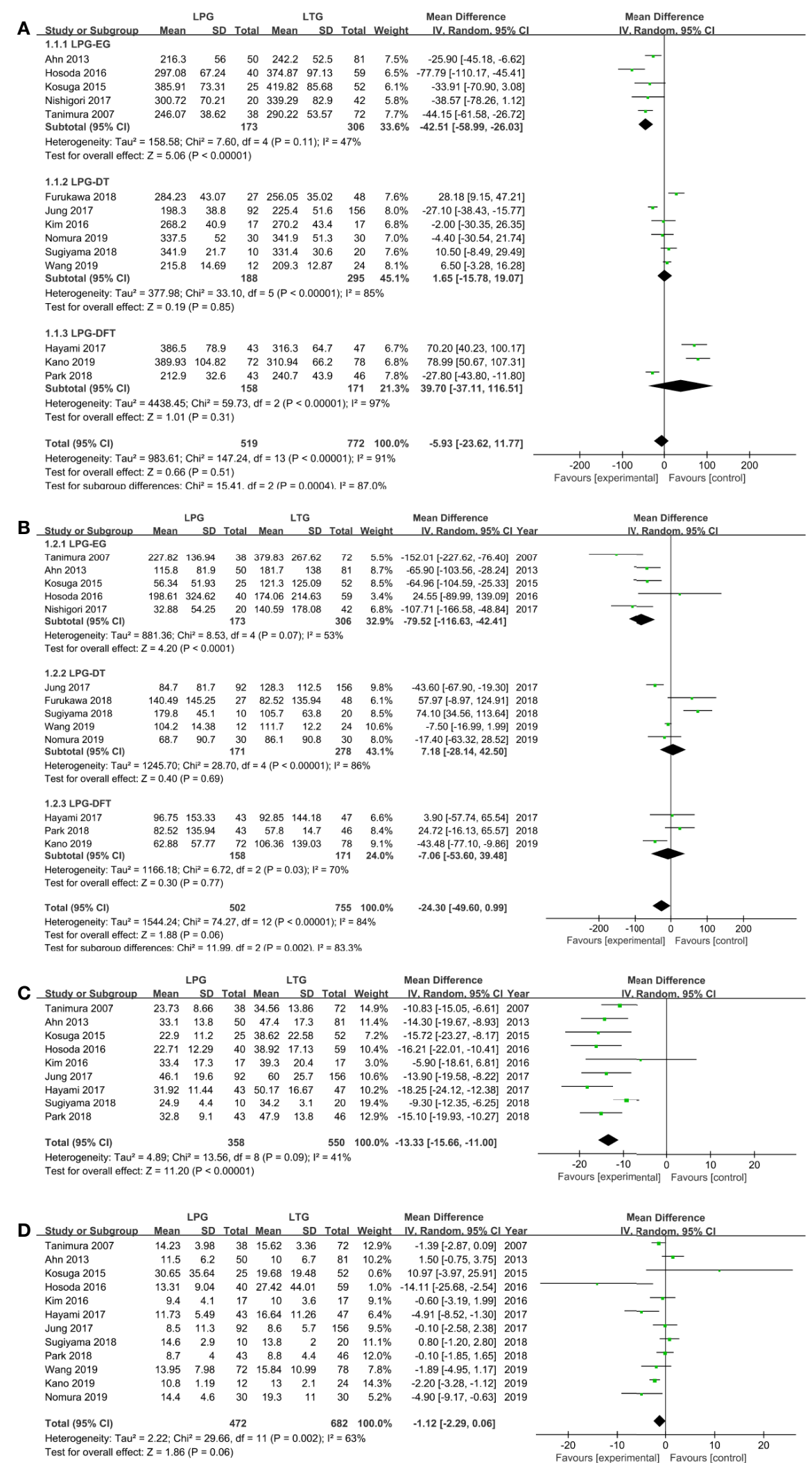

FIGURE 2 | Meta-analysis comparing (A) operative time, (B) intraoperative blood loss, (C) harvested lymph nodes, (D) postoperative hospital stay. 
complexity of the procedures performed in LTG and LPG-DT/ DFT. During these procedures, abundant major nutritional vessels need to be identified, and numerous anatomic plans, complicated anastomosis methods, and extensive lymph node dissection need to be performed (44). Another explanation is that for surgeons performing these procedures, a complex learning curve is required to acquire proficiency. Cases performed by surgeons with less experience may take longer than subsequent cases performed by the same surgeon do due differences in skill $(45,46)$.

Because of its aggressive nature, proximal gastric cancer is usually diagnosed at a more advanced stage of the disease than is observed in distal gastric cancer (47). Thus, extended lymph node dissection and the number of harvested lymph nodes should be used to evaluate oncologic adequacy. The newly published Japanese Gastric Cancer Treatment Guidelines 2014 (ver. 4) recommend that proximal gastrectomy is only suitable for some early-stage diseases (44). Applying all aspects of the American Joint Committee on Cancer (AJCC) tumor, nodes, and metastasis (TNM) classification requires that the number of lymph nodes examined be at least 15 . Based on our research, the mean number of lymph nodes retrieved by the two procedures was adequate in all included studies. In our analysis, we discovered that more lymph nodes were harvested during LTG than LPG, but no prognostic difference was observed between the groups. This result is in line with those presented in other similar studies $(9,12,15,19)$.

The incidence of postoperative complications is widely recognized as an important indicator of surgical safety. When considering the advantages of minimally invasive surgery and function-preserving procedures, LPG is theoretically a better option than LTG. However, most gastric surgeons are reluctant to perform proximal gastrectomy because of its two well-established complications: reflux and anastomotic stricture, or so-called anastomosis-related late complications (48, 49). Direct anastomosis between the esophagus and gastric remnant allows gastric acid to easily reflux to the esophagus, causing heartburn and regurgitation in some patients. Stricture may be due to the ischemia and inflammation caused by reflux at the anastomotic site, leading to fibrosis (12). In our analysis, we found that the incidence of anastomotic strictures was significantly higher in the LPG group than in the LTG group. In the subgroup analysis, the incidence rate of reflux esophagitis was also higher in the LPG-EG group ( $P=$ $0.004)$. These results corroborate the findings of many previous studies $(12,20,21,50)$. However, one of the more significant findings to emerge from this study is that LPG-DT has an incidence of reflux esophagitis similar to that of LTG. Hence, LPG-DT appears to be a safe, effective, and reliable reconstruction method with excellent postoperative outcomes in terms of preventing reflux symptoms.

The cancer recurrence and long-term survival rates are two visually effective outcomes for evaluating surgical interventions in oncological therapy. In this meta-analysis, we extracted 5-year overall survival (OS) from available articles. Based on our results, postoperative cancer recurrence and 5-year OS were similar between the LPG group and the LTG group, consistent with previous studies $(9,12)$.

Our study has novelty and multiple strengths. First, previous studies have focused only on open surgery and did not evaluate laparoscopic surgery. With the development of laparoscopic techniques, the application of laparoscopic gastrectomy has been widely accepted, and several high-quality articles comparing LPG with LTG have recently been published. We therefore performed this meta-analysis to estimate the efficacy and safety of the two procedures in patients with proximal gastric cancer. Second, we performed a subgroup analysis of patients with different reconstruction methods according to the subgroup analysis, different types of surgical procedure had different outcomes. To the best of our knowledge, this concern was largely absent from the current study. We believe that our findings can provide surgeons with valuable information when a minimally invasive surgical option is being considered.

There are several limitations that should be considered in this meta-analysis. First, the main body of literature in the current meta-analysis was observational, which may be mixed with some sources of bias. Second, all studies included were conducted in

TABLE 2 | Meta-analysis results of endpoints from all available studies.

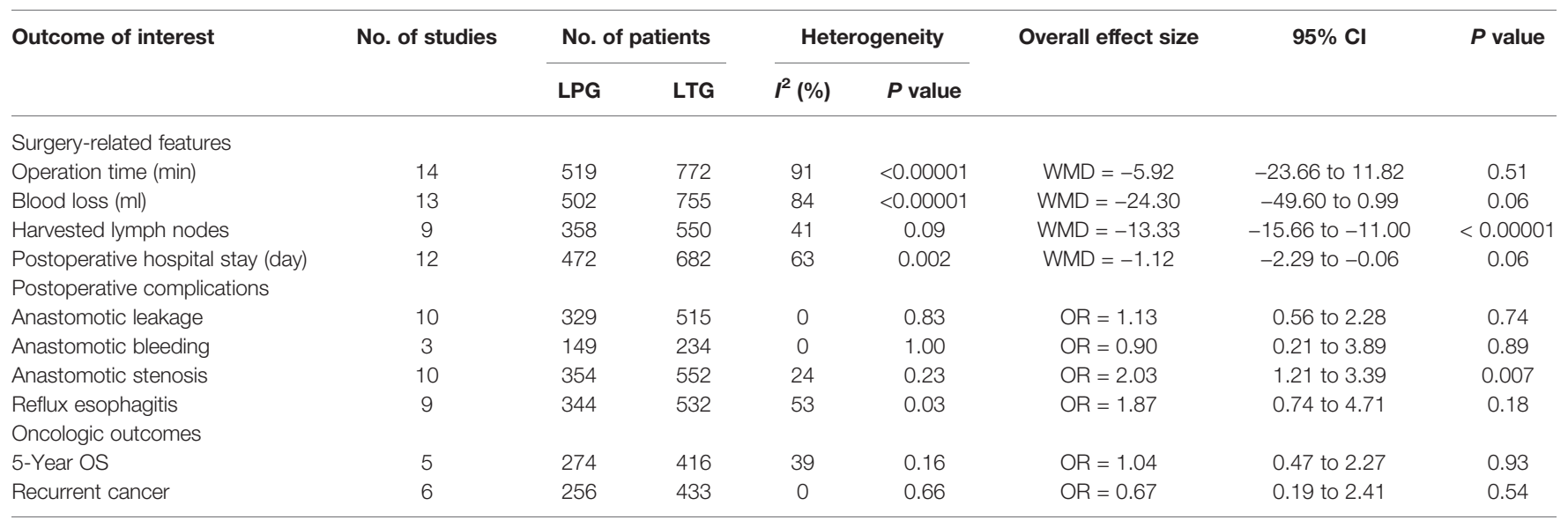

LPG, laparoscopic proximal gastrectomy; LTG, laparoscopic total gastrectomy; WMD, weighted mean difference; OR, odds ratio; OS, overall survival. 


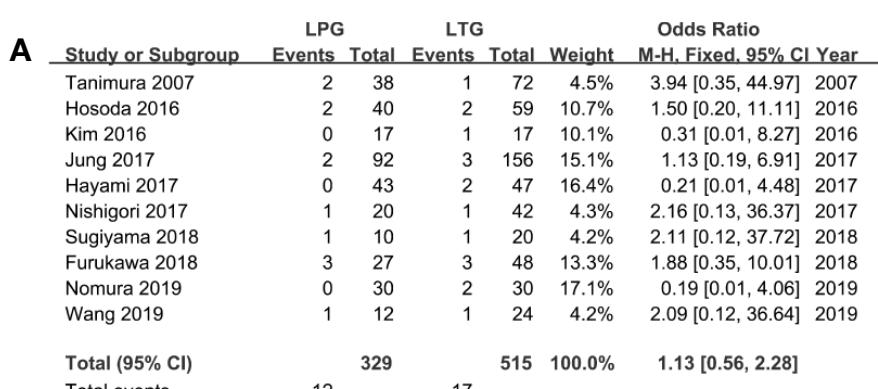

$\begin{array}{llc}\text { Total events } & 12 & 17 \\ \text { Heterogeneity: } \mathrm{Chi}^{2}=5.07, \mathrm{df}=9(\mathrm{P}=0.83) ; \mathrm{I}^{2}=0 \%\end{array}$

Heterogeneity: $\mathrm{Chi}^{2}=5.07, \mathrm{df}=9(P=0.83)$
Test for overall effect: $Z=0.33(P=0.74)$

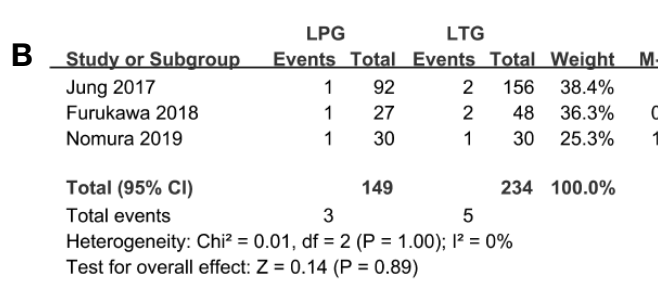

Odds Ratio

Odds Ratio

M-H. Fixed. $95 \% \mathrm{Cl}$

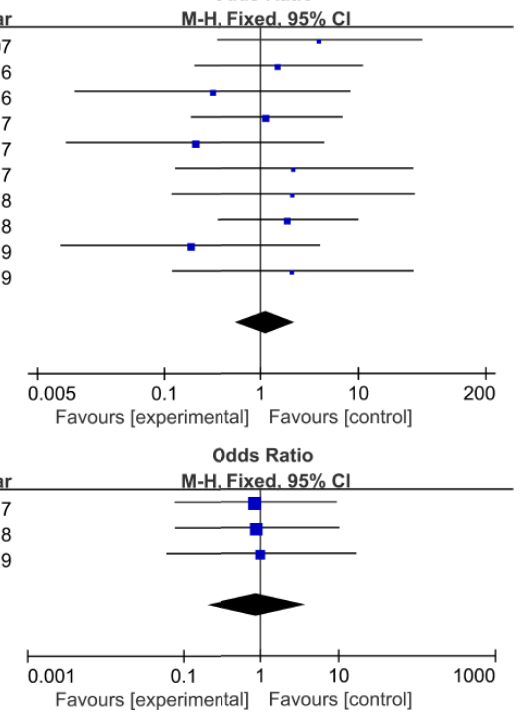

Favours [experimental] Favours [control]

Odds Ratio

$\begin{array}{cccc}\text { LPG } & \text { LTG } & \text { Odds Ratio } \\ \text { Study or Subgroup Events Total Events Total Weight } & \text { M-H. Fixed. 95\% Cl Year }\end{array}$ \begin{tabular}{llllllll}
\hline Ahn 2013 & 6 & 50 & 4 & 81 & $13.5 \%$ & $2.63[0.70,9.81] 2013$
\end{tabular} Kosuga 2015 Kim 2016

Hosoda 2016 Hayami 2017 Jung 2017 Nishigori 2017 Sugiyama 2018

Furukawa 2018 Nomura 2019

Total $(95 \% \mathrm{Cl})$

$\begin{array}{lll}\text { Total events } & 33 & 26 \\ \text { Heterogeneity: } \mathrm{Chi}^{2}=11.78, \mathrm{df}=9(\mathrm{P}=0.23) ; \mathrm{I}^{2}=24 \%\end{array}$

Test for overall effect: $Z=2.69(P=0.007)$

D LPG

LPG LTG $52 \quad 13.7 \%$ $\begin{array}{lll}52 & 13.7 \% \\ 17 & 7.3 \%\end{array}$ $59 \quad 14.7 \%$ $\begin{array}{lll}5 & 59 & 14.7 \% \\ 6 & 47 & 27.4 \%\end{array}$ $\begin{array}{lllll}0 & 42 & 1.2 \% & 30.16[1.57,577.93] & 2017\end{array}$ $\begin{array}{llll}1 & 20 & 4.9 \% & 0.62[0.02,16.57] \\ 2018\end{array}$ $0.85[0.08,9.46] 2017$ $0.88[0.08,10.23] 2018$ $1.00[0.06,16.76] 2019$

$0.90[0.21,3.89]$ $1.79[0.44,7.35] 2015$ $0.31[0.01,8.27] 2016$

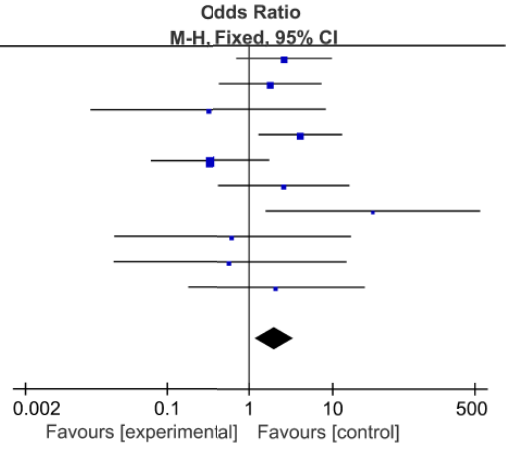

Favours [experimental] Favours [control]

Odds Ratio

\begin{tabular}{lrrrrrrr} 
Study or Subgroup & Events & Total & Events & Total & Weight & M-H. Random. 95\% Cl Year \\
\hline 2.4.1 LPG-EG & 16 & 50 & 3 & 81 & $15.5 \%$ & $12.24[3.34,44.77] 2013$ \\
Ahn 2013 & 4 & 25 & 5 & 52 & $14.6 \%$ & $1.79[0.44,7.35]$ & 2015 \\
Kosuga 2015 & 4 & 40 & 3 & 59 & $13.6 \%$ & $2.07[0.44,9.82] 2016$ \\
Hosoda 2016 & 5 & 20 & 3 & 42 & $13.7 \%$ & $4.33[0.92,20.42]$ & 2017 \\
Nishigori 2017 & & 135 & & 234 & $57.4 \%$ & $3.92[1.56,9.83]$ &
\end{tabular}

Subtotal $(95 \% \mathrm{Cl})$

Total events

29

14

Heterogeneity: $\mathrm{Tau}^{2}=0.33 ; \mathrm{Chi}^{2}=4.84, \mathrm{df}=3(\mathrm{P}=0.18) ; \mathrm{I}^{2}=38 \%$ Test for overall effect: $Z=2.91(P=0.004)$

2.4.2 LPG-DT

Kim 2016 Jung 2017

Furukawa 2018

Nomura 2019

Subtotal $(95 \% \mathrm{Cl})$

Total events

Heterogeneity: $\mathrm{Tau}^{2}=0.00 ; \mathrm{Chi}^{2}=2.10, \mathrm{df}=3(\mathrm{P}=0.55) ;\left.\right|^{2}=0 \%$

Test for overall effect: $Z=0.31(P=0.76)$

2.4.3 LPG-DFT

Hayami 2017

Subtotal $(95 \% \mathrm{Cl})$

Total events

Test for overall effect: $Z=1.83(P=0.07)$

Total $(95 \% \mathrm{Cl})$

344

35

$\begin{array}{rrrrr}2 & 17 & 1 & 17 & 8.4 \% \\ 1 & 92 & 3 & 156 & 9.4 \% \\ 2 & 27 & 1 & 48 & 8.7 \%\end{array}$

$\begin{array}{rrr}30 & 5.9 \% \\ & 251 & 32.5 \%\end{array}$ $3.76[0.32,43.53] 2018$
$0.32[0.01,8.24] 2019$

$2.13[0.17,26.03] 2016$ $0.56[0.06,5.47] 2017$ $1.22[0.34,4.37]$

Total events 27

$532100.0 \%$

$1.87[0.74,4.71]$

Heterogeneity: $\mathrm{Tau}^{2}=1.00 ; \mathrm{Chi}^{2}=17.03, \mathrm{df}=8(\mathrm{P}=0.03) ; \mathrm{I}^{2}=53 \%$

Test for overall effect: $Z=1.33(P=0.18)$

Test for subaroun differences: $\mathrm{Chi}^{2}=8.68 . \mathrm{df}=2(\mathrm{P}=0.01) . \mathrm{I}^{2}=77.0 \%$
Odds Ratio

M-H. Random, $95 \% \mathrm{Cl}$

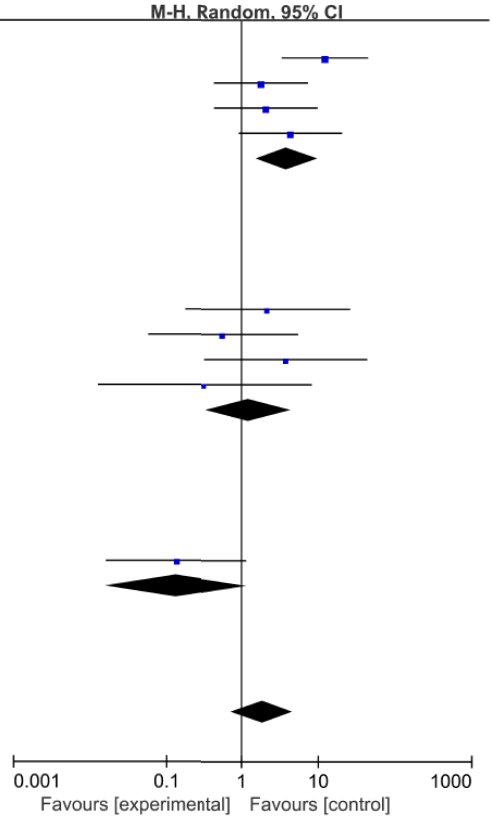

FIGURE 3 | Meta-analysis comparing (A) anastomotic leakage, (B) anastomotic bleeding, (C) anastomotic stenosis, (D) reflux esophagitis. 


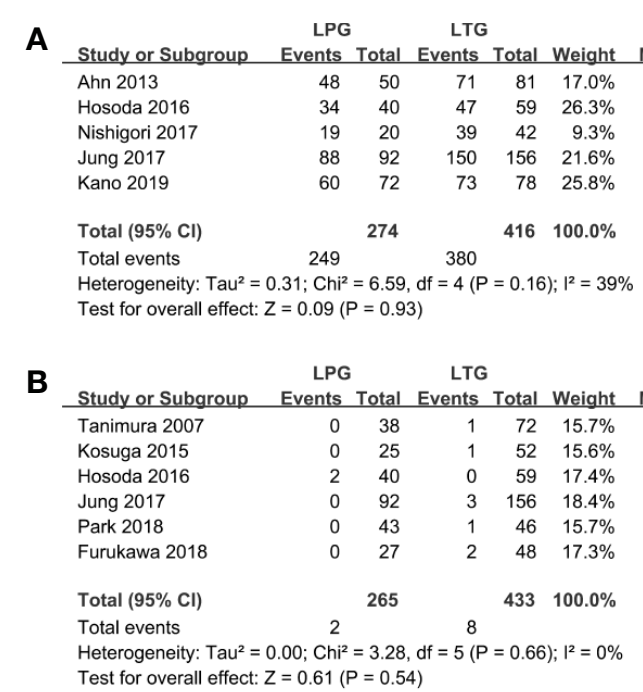

Odds Ratio

H. Random. $95 \%$ Cl Year $3.38[0.71,16.11] 2013$ $1.45[0.49,4.24] 2016$ $1.46[0.14,15.00] 2017$

$0.88[0.24,3.20] 2017$

$0.34[0.11,1.03] 2019$

$1.04[0.47,2.27]$

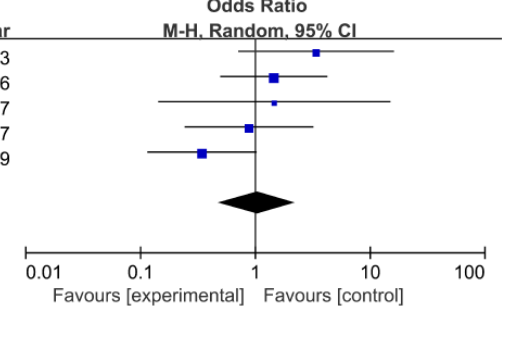

Odds Ratio

-H. Random. 95\% Cl Year $0.62[0.02,15.56] 2007$ $0.67[0.03,17.11] 2015$

$7.73[0.36,165.35] 2016$ $0.24[0.01,4.64] 2017$ $0.35[0.01,8.79] 2018$ $0.34[0.02,7.31] 2018$

$0.67[0.19,2.41]$
Odds Ratio

M-H. Random, $95 \% \mathrm{Cl}$

Odds Ratio

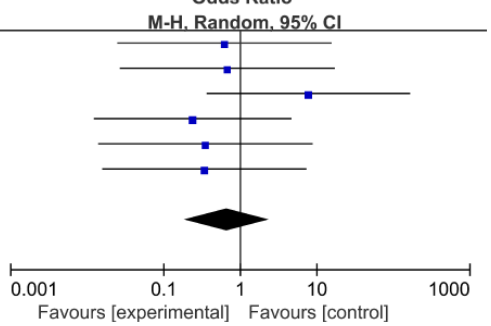

Heterogeneity: $\mathrm{Tau}^{2}=0.00 ; \mathrm{Chi}^{2}=3.28, \mathrm{df}=5(\mathrm{P}=0.66) ; \mathrm{I}^{2}=0 \%$

FIGURE 4 | Meta-analysis comparing (A) 5-year OS, (B) recurrent cancer.

\section{A Operation time}

Begg's funnel plot with pseudo $95 \%$ confidence limits

100

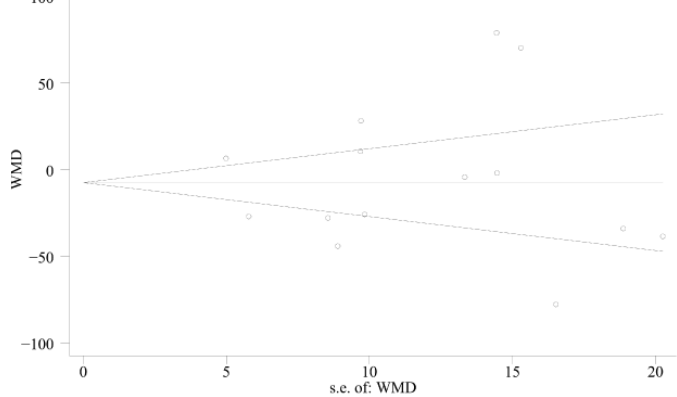

$t=0.21 ; P=0.841 ; 95 \%$ Cl: -4.53 to 5.48

C Harvested lymph nodes

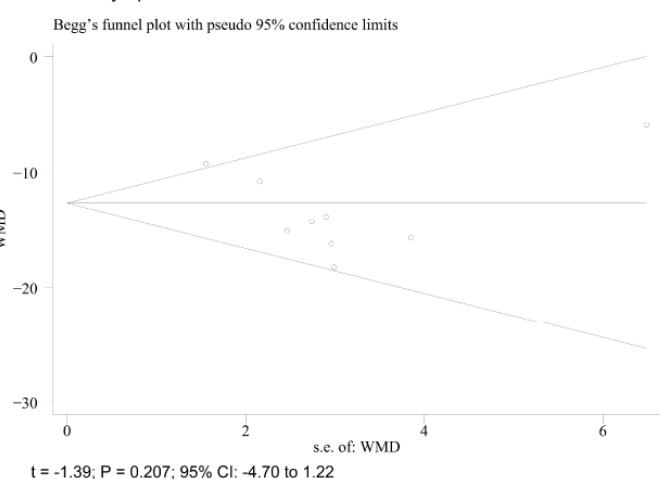

B Blood loss

Begg's funnel plot with pseudo $95 \%$ confidence limits$$
100
$$

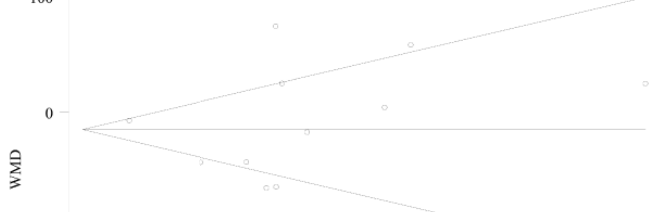

$-100$

$-200$

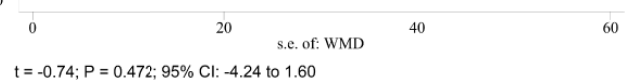

$t=-0.74 ; P=0.472 ; 95 \% \mathrm{Cl}:-4.24$ to 1.60

D Postoperative hospital stay

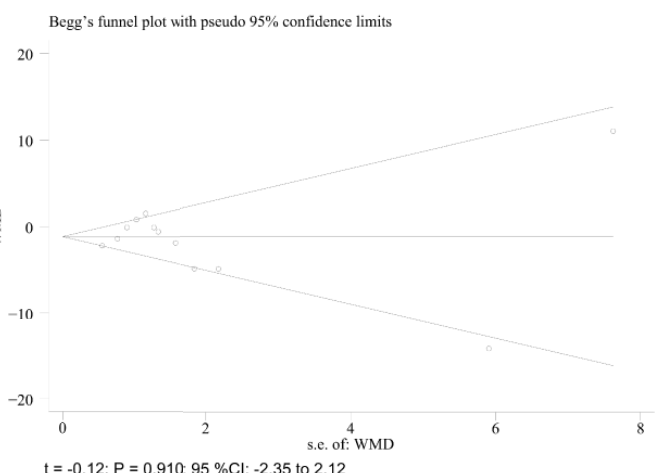

FIGURE 5 | Funnel plots of each outcome. (A) operative time; (B) blood loss; (C) harvested lymph nodes; (D) postoperative hospital. 
East Asian countries, potentially due to the high incidence of gastric cancer in eastern countries. The conclusions might therefore be biased toward Asian populations, and it may therefore be difficult to generalize these findings to other populations. Last, there was high heterogeneity in terms of operation time, blood loss and postoperative hospital stay. Differences in study design, sample size, and digestive tract reconstruction might explain this heterogeneity. Therefore, the addition of high-quality, multicenter, randomized, controlled trials from other countries and regions are needed to further clarify these issues.

\section{CONCLUSIONS}

Because it produces fewer harvested lymph nodes and has a similar oncological safety profile, LPG can be performed as an alternative to LTG, especially LPG-DT/DFT, for proximal gastric cancer and has comparable safety and efficacy. Additional high-quality randomized controlled trials including Western patients and surgeons are still needed for further validation of these results.

\section{REFERENCES}

1. Bray F, Ferlay J, Soerjomataram I, Siegel RL, Torre LA, Jemal A. Global cancer statistics 2018: GLOBOCAN estimates of incidence and mortality worldwide for 36 cancers in 185 countries. CA Cancer J Clin (2018) 68:394-424. doi: $10.3322 /$ caac. 21492

2. Van Cutsem E, Sagaert X, Topal B, Haustermans K, Prenen H. Gastric cancer. Lancet (2016) 388:2654-64. doi: 10.1016/S0140-6736(16)30354-3

3. Ahn HS, Lee HJ, Yoo MW, Jeong SH, Park DJ, Kim HH, et al. Changes in clinicopathological features and survival after gastrectomy for gastric cancer over a 20-year period. Br J Surg (2011) 98:255-60. doi: 10.1002/bjs.7310

4. Shen L, Shan YS, Hu HM, Price TJ, Sirohi B, Yeh KH, et al. Management of gastric cancer in Asia: resource-stratified guidelines. Lancet Oncol (2013) 14: e535-47. doi: 10.1016/S1470-2045(13)70436-4

5. Ajani JA, D'Amico TA, Almhanna K, Bentrem DJ, Chao J, Das P, et al. Gastric Cancer, Version 3.2016, NCCN Clinical Practice Guidelines in Oncology. J Natl Compr Canc Netw (2016) 14:1286-312. doi: 10.6004/jnccn.2016.0137

6. Liakakos T, Roukos D. Laparoscopic gastrectomy: advances enable wide clinical application. Surg Endosc (2008) 22:1553-5. doi: 10.1007/s00464008-9869-0

7. Shiraishi N, Yasuda K, Kitano S. Laparoscopic gastrectomy with lymph node dissection for gastric cancer. Gastric Cancer (2006) 9:167-76. doi: 10.1007/ s10120-006-0380-9

8. Kunisaki C, Makino H, Takagawa R, Kimura J, Ota M, Ichikawa Y, et al. A systematic review of laparoscopic total gastrectomy for gastric cancer. Gastric Cancer (2015) 18:218-26. doi: 10.1007/s10120-015-0474-3

9. Sugoor P, Shah S, Dusane R, Desouza A, Goel M, Shrikhande SV. Proximal gastrectomy versus total gastrectomy for proximal third gastric cancer: total gastrectomy is not always necessary. Langenbecks Arch Surg (2016) 401:68797. doi: 10.1007/s00423-016-1422-3

10. Harrison LE, Karpeh MS, Brennan MF. Total gastrectomy is not necessary for proximal gastric cancer. Surgery (1998) 123:127-30. doi: 10.1016/S0039-6060 (98)70248-X

11. Katai H, Morita S, Saka M, Taniguchi H, Fukagawa T. Long-term outcome after proximal gastrectomy with jejunal interposition for suspected early cancer in the upper third of the stomach. Br J Surg (2010) 97:558-62. doi: 10.1002/bjs.6944

12. An JY, Youn HG, Choi MG, Noh JH, Sohn TS, Kim S. The difficult choice between total and proximal gastrectomy in proximal early gastric cancer. Am J Surg (2008) 196:587-91. doi: 10.1016/j.amjsurg.2007.09.040

\section{DATA AVAILABILITY STATEMENT}

The original contributions presented in the study are included in the article/supplementary materials, further inquiries can be directed to the corresponding author.

\section{AUTHOR CONTRIBUTIONS}

PT, PZ, and ZZ designed the study. SB, ML, MZ, and JL were involved in literature search and data interpretation. YL and LJ analyzed the data. PT wrote the manuscript. All authors contributed to the article and approved the submitted version.

\section{FUNDING}

This work was supported in part by grants from the National Key Technologies R\&D Program (No. 2015BAI13B09) and the National Key Technologies R\&D Program of China (No. 2017YFC0110904).

13. Ahn SH, Lee JH, Park DJ, Kim HH. Laparoscopy-assisted proximal gastrectomy for early gastric cancer is an ugly duckling with unsolved concerns: oncological safety, late complications, and functional benefit. Gastric Cancer (2013) 16:448-50. doi: 10.1007/s10120-013-0245-y

14. Hiki N. Present features and future vision of laparoscopy-assisted total gastrectomy (LATG). Gastric Cancer (2013) 16:460-1. doi: 10.1007/s10120-013-0286-2

15. Carey S, Storey D, Biankin AV, Martin D, Young J, Allman-Farinelli M. Long term nutritional status and quality of life following major upper gastrointestinal surgery - a cross-sectional study. Clin Nutr (2011) 30:774-9. doi: 10.1016/j.clnu.2011.03.003

16. Aoyama T, Yoshikawa T, Maezawa Y, Segami K, Kano K, Numata M, et al. Influence of Postoperative Surgical Complications After Gastrectomy on Body Weight and Body Composition Changes in Patients With Gastric Cancer. Anticancer Res (2019) 39:1073-8. doi: 10.21873/anticanres.13215

17. Fein M, Fuchs KH, Thalheimer A, Freys SM, Heimbucher J, Thiede A. Long-term benefits of Roux-en-Y pouch reconstruction after total gastrectomy: a randomized trial. Ann Surg (2008) 247:759-65. doi: 10.1097/SLA.0b013e318167748c

18. Huh YJ, Lee HJ, Oh SY, Lee KG, Yang JY, Ahn HS, et al. Clinical Outcome of Modified Laparoscopy-Assisted Proximal Gastrectomy Compared to Conventional Proximal Gastrectomy or Total Gastrectomy for Upper-Third Early Gastric Cancer with Special References to Postoperative Reflux Esophagitis. J Gastric Cancer (2015) 15:191-200. doi: 10.5230/jgc.2015.15.3.191

19. Yoo CH, Sohn BH, Han WK, Pae WK. Long-term results of proximal and total gastrectomy for adenocarcinoma of the upper third of the stomach. Cancer Res Treat (2004) 36:50-5. doi: 10.4143/crt.2004.36.1.50

20. Ronellenfitsch U, Najmeh S, Andalib A, Perera RM, Rousseau MC, Mulder DS, et al. Functional outcomes and quality of life after proximal gastrectomy with esophagogastrostomy using a narrow gastric conduit. Ann Surg Oncol (2015) 22:772-9. doi: 10.1245/s10434-014-4078-7

21. Nakamura M, Nakamori M, Ojima T, Katsuda M, Iida T, Hayata K, et al. Reconstruction after proximal gastrectomy for early gastric cancer in the upper third of the stomach: an analysis of our 13-year experience. Surgery (2014) 156:57-63. doi: 10.1016/j.surg.2014.02.015

22. Ichikawa D, Komatsu S, Kubota T, Okamoto K, Shiozaki A, Fujiwara H, et al. Long-term outcomes of patients who underwent limited proximal gastrectomy. Gastric Cancer (2014) 17:141-5. doi: 10.1007/s10120-013-0257-7

23. Pu YW, Gong W, Wu YY, Chen Q, He TF, Xing CG. Proximal gastrectomy versus total gastrectomy for proximal gastric carcinoma. A meta-analysis on postoperative complications, 5-year survival, and recurrence rate. Saudi Med J (2013) 34:1223-8 
24. Chen YC, Lu L, Fan KH, Wang DH, Fu WH. Proximal gastrectomy versus total gastrectomy for adenocarcinoma of the esophagogastric junction: a meta-analysis. J Comp Eff Res (2019) 8:753-66. doi: 10.2217/cer-2019-0016

25. Xu Y, Tan Y, Wang Y, Xi C, Ye N, Xu X. Proximal versus total gastrectomy for proximal early gastric cancer: A systematic review and meta-analysis. Medicine (Baltimore) (2019) 98:e15663. doi: 10.1097/MD.0000000000015663

26. Wen L, Chen XZ, Wu B, Chen XL, Wang L, Yang K, et al. Total vs. proximal gastrectomy for proximal gastric cancer: a systematic review and metaanalysis. Hepatogastroenterology (2012) 59:633-40. doi: 10.5754/hge11834

27. Li S, Gu L, Shen Z, Mao D, Khadaroo PA, Su H. A meta-analysis of comparison of proximal gastrectomy with double-tract reconstruction and total gastrectomy for proximal early gastric cancer. BMC Surg (2019) 19:117. doi: 10.1186/s12893-019-0584-7

28. Wan X, Wang W, Liu J, Tong T. Estimating the sample mean and standard deviation from the sample size, median, range and/or interquartile range. BMC Med Res Methodol (2014) 14:135. doi: 10.1186/1471-2288-14-135

29. Luo D, Wan X, Liu J, Tong T. Optimally estimating the sample mean from the sample size, median, mid-range, and/or mid-quartile range. Stat Methods Med Res (2018) 27:1785-805. doi: 10.1177/0962280216669183

30. Tanimura S, Higashino M, Fukunaga Y, Kishida S, Ogata A, Fujiwara Y, et al. Laparoscopic gastrectomy with regional lymph node dissection for upper gastric cancer. Br J Surg (2007) 94:204-7. doi: 10.1002/bjs.5542

31. Ahn SH, Lee JH, Park DJ, Kim HH. Comparative study of clinical outcomes between laparoscopy-assisted proximal gastrectomy (LAPG) and laparoscopy-assisted total gastrectomy (LATG) for proximal gastric cancer. Gastric Cancer (2013) 16:282-9. doi: 10.1007/s10120-012-0178-x

32. Kosuga T, Ichikawa D, Komatsu S, Okamoto K, Konishi H, Shiozaki A, et al. Feasibility and Nutritional Benefits of Laparoscopic Proximal Gastrectomy for Early Gastric Cancer in the Upper Stomach. Ann Surg Oncol (2015) 22 Suppl 3:S929-35. doi: 10.1245/s10434-015-4590-4

33. Kim DJ, Kim W. Laparoscopy-assisted Proximal Gastrectomy with Double Tract Anastomosis Is Beneficial for Vitamin B12 and Iron Absorption. Anticancer Res (2016) 36:4753-8. doi: 10.21873/anticanres.11031

34. Hosoda K, Oho AUID-, Yamashita K, Katada N, Moriya H, Mieno H, et al. Potential benefits of laparoscopy-assisted proximal gastrectomy with esophagogastrostomy for cT1 upper-third gastric cancer. Surg Endosc (2016) 30:3426-36. doi: 10.1007/s00464-015-4625-8

35. Jung DH, Lee Y, Kim DW, Park YS, Ahn SH, Park DJ, et al. Laparoscopic proximal gastrectomy with double tract reconstruction is superior to laparoscopic total gastrectomy for proximal early gastric cancer. Surg Endosc (2017) 31:3961-9. doi: 10.1007/s00464-017-5429-9

36. Nishigori T, Okabe H, Tsunoda S, Shinohara H, Obama K, Hosogi H, et al. Superiority of laparoscopic proximal gastrectomy with hand-sewn esophagogastrostomy over total gastrectomy in improving postoperative body weight loss and quality of life. Surg Endosc (2017) 31:3664-72. doi: 10.1007/s00464-016-5403-y

37. Park JY, Park KB, Kwon OK, Yu W. Comparison of laparoscopic proximal gastrectomy with double-tract reconstruction and laparoscopic total gastrectomy in terms of nutritional status or quality of life in early gastric cancer patients. Eur J Surg Oncol (2018) 44:1963-70. doi: 10.1016/j.ejso.2018.08.014

38. Sugiyama M, Oki E, Ando K, Nakashima Y, Saeki H, Maehara Y. Laparoscopic Proximal Gastrectomy Maintains Body Weight and Skeletal Muscle Better Than Total Gastrectomy. World J Surg (2018) 42:3270-6. doi: 10.1007/s00268-018-4625-7

39. Furukawa H, Kurokawa Y, Takiguchi S, Tanaka K, Miyazaki Y, Makino T, et al. Short-term outcomes and nutritional status after laparoscopic subtotal gastrectomy with a very small remnant stomach for cStage I proximal gastric carcinoma. Gastric Cancer (2018) 21:500-7. doi: 10.1007/s10120-017-0755-0

40. Nomura E, Kayano H, Lee SW, Kawai M, Machida T, Yamamoto S, et al. Functional evaluations comparing the double-tract method and the jejunal interposition method following laparoscopic proximal gastrectomy for gastric cancer: an investigation including laparoscopic total gastrectomy. Surg Today (2019) 49:38-48. doi: 10.1007/s00595-018-1699-7

41. Kano Y, Ohashi M, Ida S, Kumagai K, Nunobe S, Sano T, et al. Oncological feasibility of laparoscopic subtotal gastrectomy compared with laparoscopic proximal or total gastrectomy for CT1N0M0 gastric cancer in the upper gastric body. Gastric Cancer (2019) 22:1060-8. doi: 10.1007/s10120-019-00947-7

42. Hayami M, Hiki N, Nunobe S, Mine S, Ohashi M, Kumagai K, et al. Clinical Outcomes and Evaluation of Laparoscopic Proximal Gastrectomy with DoubleFlap Technique for Early Gastric Cancer in the Upper Third of the Stomach. Ann Surg Oncol (2017) 24:1635-42. doi: 10.1245/s10434-017-5782-x

43. Wang L, Xia Y, Jiang T, Li F, Wang W, Zhang D, et al. Short-Term Surgical Outcomes of Laparoscopic Proximal Gastrectomy With Double-Tract Reconstruction Versus Laparoscopic Total Gastrectomy for Adenocarcinoma of Esophagogastric Junction: A Matched-Cohort Study. J Surg Res (2020) 246:292-9. doi: $10.1016 /$ j.jss.2019.09.022

44. Japanese gastric cancer treatment guidelines 2014 (ver. 4). Gastric Cancer (2017) 20:1-19. doi: 10.1007/s10120-016-0622-4

45. Jung DH, Son SY, Park YS, Shin DJ, Ahn HS, Ahn SH, et al. The learning curve associated with laparoscopic total gastrectomy. Gastric Cancer (2016) 19:264-72. doi: 10.1007/s10120-014-0447-y

46. Jeong O, Ryu SY, Choi WY, Piao Z, Park YK. Risk factors and learning curve associated with postoperative morbidity of laparoscopic total gastrectomy for gastric carcinoma. Ann Surg Oncol (2014) 21:2994-3001. doi: 10.1245/s10434014-3666-x

47. Piso P, Werner U, Lang H, Mirena P, Klempnauer J. Proximal versus distal gastric carcinoma-what are the differences. Ann Surg Oncol (2000) 7:520-5. doi: 10.1007/s10434-000-0520-0

48. Hoshikawa T, Denno R, Ura H, Yamaguchi K, Hirata K. Proximal gastrectomy and jejunal pouch interposition: evaluation of postoperative symptoms and gastrointestinal hormone secretion. Oncol Rep (2001) 8:1293-9. doi: 10.3892/or.8.6.1293

49. Yoo CH, Sohn BH, Han WK, Pae WK. Proximal gastrectomy reconstructed by jejunal pouch interposition for upper third gastric cancer: prospective randomized study. World J Surg (2005) 29:1592-9. doi: 10.1007/s00268005-7793-1

50. Katai H, Sano T, Fukagawa T, Shinohara H, Sasako M. Prospective study of proximal gastrectomy for early gastric cancer in the upper third of the stomach. Br J Surg (2003) 90:850-3. doi: 10.1002/bjs.4106

Conflict of Interest: The authors declare that the research was conducted in the absence of any commercial or financial relationships that could be construed as a potential conflict of interest.

Copyright (c) 2021 Tian, Liu, Bian, Li, Zhang, Liu, Jin, Zhang and Zhang. This is an open-access article distributed under the terms of the Creative Commons Attribution License (CC BY). The use, distribution or reproduction in other forums is permitted, provided the original author(s) and the copyright owner(s) are credited and that the original publication in this journal is cited, in accordance with accepted academic practice. No use, distribution or reproduction is permitted which does not comply with these terms. 